\title{
The Role and Contribution of Philanthropy to the Lives of Older People in Ireland
}

\author{
Andy Cochrane, National University of Ireland Maynooth, Ireland \\ Sinéad McGilloway, National University of Ireland Maynooth, Ireland \\ Mairéad Furlong, National University of Ireland Maynooth, Ireland \\ Michael Donnelly, Queen’s University Belfast, Northern Ireland
}

\begin{abstract}
This paper examines the impact, since 2008, of an international philanthropic organisation on the ageing sector in the Republic of Ireland. Several methods were used in a sector-wide evaluation, including documentary analysis, one-to-one in-depth interviews, a cross-sectional survey of grant-holders, and collaborative work with Northern Ireland. There was a relative lack of strategic focus on older people before the philanthropic work began; evidence for policy and planning was limited and advocacy was small-scale and largely uncoordinated. This may have been because the Republic of Ireland had the lowest proportion of people aged $\geq 65$ in the EU. The findings show that philanthropy has played a pivotal role in enhancing capacity, infrastructure and expertise through large-scale investment in research and training, strengthening older people's organisations and developing centres of excellence. Important initiatives include a national longitudinal ageing study, a commitment to develop a positive ageing strategy and roll-out of the Age Friendly Counties programme. The sustainability of these notable achievements relies on a sector-wide collaborative ethos, translating evidence into practice, actively involving older people and securing support from the academic, health and government sectors. Overall, the philanthropic organisation has contributed significantly to Ireland's efforts to develop innovative, evidence-based ageing strategies and policies.
\end{abstract}

Keywords: Philanthropy, Positive Ageing, Age Friendly, Ageing Research, Policy

\section{Introduction}

7 The most recent Census results from the Republic of Ireland (Ireland) show that the number of people aged $\geq 65$ has increased by 14 per cent since 2006 (Central Statistics Office; CSO 2012, 26); this is likely to continue to increase dramatically over the next 30 years, with the number of 'oldest-old' expected to quadruple from 110,000 in 2006 to 440,000 in 2041 (CSO 2007, 11). Despite much of the alarmist rhetoric (e.g., "demographic time-bomb”), Ireland still lags behind most western countries in population ageing and is uniquely placed, therefore, to develop innovative ageing strategies (Pierce, Fitzgerald and Timonen 2010, 2). This paper examines the role that the Atlantic Philanthropies (Atlantic) has played in transforming the ageing sector in Ireland and in creating a landscape that has the potential to support positive, healthy ageing.

Atlantic is a limited life foundation (1982-2020) that has, so far, made grants totalling \$6.1 billion through Ageing, Children and Youth, Population Health and Reconciliation programmes in seven countries ${ }^{1}$. Atlantic's philosophy and grant-making seek to advance opportunity and promote lasting change in the lives of disadvantaged and vulnerable people. The Ageing Programme in Ireland was established in 2003 in order to enhance the rights of all older people to health and economic security and to enable them to advocate for a better quality of life for themselves and their peers. Between 2008 and 2011, Atlantic has focussed its grant-making strategies on three main objectives as outlined in Table 1 . It should be noted that there is considerable overlap between the objectives, and this should be borne in mind when considering the number of grants awarded. Further details regarding the organisations funded and amounts awarded, can be found at www.atlanticphilanthropies.org.

\footnotetext{
${ }^{1}$ The other countries are Bermuda, Northern Ireland, South Africa, USA, Vietnam and Australia.
}

The International Journal of Aging and Society

Volume 2, 2013, www.aging andsociety.com, ISSN 2160-1909

(C) Common Ground, Andy Cochrane, Sinéad McGilloway, Mairéad Furlong,

Michael Donnelly, All Rights Reserved

Permissions: cg-support@commongroundpublishing.com 
Table 1: Objectives for the Ireland Ageing Programme 2008-2011

\begin{tabular}{|l|l|l|}
\hline Objective & Number of grants & Number of organisations \\
\hline $\begin{array}{l}\text { Build a more enduring } \\
\text { capacity of the age sector }\end{array}$ & 7 & 5 \\
\hline $\begin{array}{l}\text { Strengthen the voice and } \\
\text { social action of older people. }\end{array}$ & 18 & 10 \\
\hline $\begin{array}{l}\text { Improve health and economic } \\
\text { security for older people }\end{array}$ & 18 & 9 \\
\hline & 44 & 22 \\
\hline
\end{tabular}

*Grants may be aligned to more than one of the above objectives in which case, they have been counted only once.

The overall emphasis of the objectives on building capacity across voluntary and research organisations reflects the underdeveloped state of the ageing sector at the beginning of the grantmaking period. Specifically, Atlantic operated in a context whereby public advocacy for older people was undertaken by a very small number of largely fragmented and un-coordinated organisations and agencies, with an attendant lack of effective advocacy for vulnerable older people (e.g. O'Neill and O'Keefe 2003, 1281; National Economic and Social Forum 2005, 28). Furthermore, while there has been a history of age-specific policy initiatives (e.g., The Years Ahead: a Policy for the Elderly 1988), it has been argued that overall, there has been a low level of awareness of ageing as a core government policy issue (O'Neill Twomey and O'Shea 2009, 283). The subsequent lack of planning and provision for an ageing population has been further hampered by a lack of national datasets, with a dearth of information about the experience of ageing in Ireland (O’Shea and Conboy 2005, 4).

More recently, the demise of the 'Celtic Tiger' economy, and the austerity measures taken by the Irish government in the context of the ongoing financial and economic crisis, have seriously curtailed social and health-care spending. This is likely to have ongoing negative consequences for vulnerable older citizens. The challenges associated with increasing numbers of older persons during a period of economic uncertainty are not unique to Ireland, of course, and as in other countries, there is an urgent need for evidence-based information about individual and societal ageing to appropriately inform policy and practice and to tackle ageist attitudes (e.g. the 'burden' and 'crisis' of ageing) at both governmental and wider societal level (Olshansky et al. 2011, 98).

\section{Method}

The current review is part of a larger evaluation designed to assess the effectiveness of Atlantic's ageing programme in terms of overall relevance, impact and sustainability. The evaluation was based on a collaborative and highly participatory approach with the aim of engaging a wide and diverse range of key stakeholders, both from the individual grantees/projects and the wider ageing sector in Ireland (e.g. service providers, academics, health and social care professionals, and government representatives/civil servants). The evaluation has focussed less on auditing, quantifying or measuring outcomes per se at the individual service level and more on monitoring processes and macro-level outcomes. Data collection is ongoing and has involved a number of key activities including: a systematic documentary analysis (project proposals, progress reports, narrative reports, research reports and other relevant outputs/documentation); a series of site visits and one-to-one interviews with key informants (including decision-makers); stakeholder workshops; case-studies; and a postal survey of grantees. All data were subjected to a standard thematic analysis and this review will focus on three inter-related elements: (1) investment in 
research infrastructure and support; (2) strengthening/enhancing older people's organisations; and (3) the implementation of large-scale initiatives similar to those undertaken in other countries. In the final section of this paper, we will consider how these map onto Atlantic's 20082011 objectives, and how, in turn, they have influenced its ongoing grant-making programme.

\section{Findings}

\section{(1) Research Infrastructure and Support}

There is a growing international consensus that advancements in the knowledge base of gerontology and scientific research should act as the driver of innovation in public policy and in developing products and services within the ageing sector (see WHO 2001; Futurage 2011). Within a European context, investment in an ageing research infrastructure, such as a European Institute of Ageing, is seen as crucial for building research capacity (Futurage 2011) and to address several weaknesses in the sector (Warnes and Phillips 2007, 139-155). For example, although there has been a growth in gerontology research since the 1970s, there has been a lack of investment at the postgraduate level and a significant lack of a career structure. In addition, most research has been undertaken within the biomedical field with insufficient inter-disciplinary liaison with social gerontology (Warnes and Phillips). Historically, the Irish higher education research infrastructure has been chronically under-funded and has lacked strategic direction. Atlantic has made a very significant contribution to strengthening the research capabilities in Ireland by investing a total of $\$ 262$ million $^{2}$ in the first three funding cycles of the Programme for Research in Third-Level Institutions (PRTLI). This programme, co-funded by the Irish government, was launched in 1998, and aimed to develop the appropriate conditions to transform the research landscape through investment in physical infrastructure and human capital. A PRTLI impact assessment and a subsequent review (Higher Education Authority 2006), revealed a transformed higher education landscape, albeit one that still lagged behind other developed nations.

It is within this context that, since 2005, Atlantic has made a significant contribution to supporting the continued expansion of ageing-related research capability and infrastructures. Four institutions, in particular, geographically spread throughout Ireland, have been involved in this transformative process. The considerable investment by Atlantic in academic research and education has gone a long way toward addressing the deficits identified by Warnes and Phillips (2007) in a number of ways. Firstly, leadership has been enhanced through the retention and recruitment of respected senior influential researchers in, for example social and medical gerontology, neuroscience, and bio-engineering. Investment in physical infrastructures in both university and clinical settings will, when completed, provide 'state of the art' facilities and provide optimal environments for training the next cadre of researchers. Furthermore, the enhanced capacity and expertise has led to an improved infrastructure for education and training at both under- and post-graduate levels. Atlantic's support in this sector, totalling over $\$ 45 \mathrm{~m}$ since 2005, is all the more impressive considering that across Europe, only a very small number of institutions have been able to raise significant funding from philanthropic sources whilst even fewer have accessed such funding to support research (Breeze et al. 2011, 1192).

Our review of two research mapping exercises conducted by the Atlantic-supported Centre for Ageing Research and Development in Ireland (CARDI 2009, 2010, 7), finds clear evidence for the emergence of Atlantic's strong and positive influence on the ageing research landscape. The first report identified 84 individual research projects which were related, at least in part, to ageing in Ireland; most of these were being conducted in universities, with a smaller number

\footnotetext{
${ }^{2}$ This is equivalent to $16 \%$ of the government's contribution of more than $€ 1.1$ billion ( $\$ 1.3$ billion) through five cycles that continue to date.
} 
from statutory (e.g., Equality Authority) and voluntary bodies (e.g., Alzheimer Society of Ireland). Significantly, $16 \%(14 / 84)$ of all the projects, even at this relatively early stage of investment, were being undertaken by researchers or voluntary bodies supported by Atlantic $(2009,6)$. Taken together, the two CARDI publications demonstrate an increased focus on agerelated research more generally, with a notable growth in specific areas of research expertise in medical gerontology and social policy. In addition, by the time of the second report, there was a notable shift towards a more strategic focus in universities that, importantly, reflects both the complexity of ageing and the need for a multi- rather than a uni-disciplinary approach (Hagan Hennessy and Walker 2011, 53). While it is difficult to determine a direct link between Atlantic's investment and the general growth of ageing research across various institutions in Ireland, it seems likely that high profile, cross-disciplinary, and inter-institutional initiatives supported by Atlantic, such as the Irish Longitudinal Study on Ageing (TILDA), have done much to establish ageing as a research priority across the country. Importantly, TILDA will continue to provide a vital piece of knowledge infrastructure that will improve the evidence base for planning, policy and research into the future. The first wave of findings (Barrett et al. 2011) has already highlighted important issues surrounding health inequalities and the prevalence and underdiagnosis of some physical and mental health conditions (e.g., obesity, hypertension, depression) in the older population. The ability to identify policy-related issues, such as the need for regular health assessments, and to track any subsequent effects of policy changes, are significant benefits of this study.

However, as in many other countries, there is often a delicate relationship between research evidence and the, ultimately, political considerations that shape policy (Nutbeam 2004). It is critical, therefore, to establish strong links and consultation with end-users of research including government, non-governmental organisations and charities (Hagan Hennessy and Walker 2011, 57). Atlantic has sought to facilitate these links through their grant-making activities, and a notable example of this has been to garner government commitment to a National Dementia Strategy. The call for this strategy has lasted several years, with an original report produced more than a decade ago (O’Shea and O’Reilly 1999). It has taken persistent lobbying from the Alzheimer Society of Ireland amongst others, and progress in Europe (e.g., the European Initiative on Dementia, 2009) to finally achieve a government commitment to developing a strategy in 2010. Atlantic has played a critical role in maintaining this momentum by bringing together a wide coalition of stakeholders and policy makers and in funding an attendant major research review which was undertaken to inform the development of this strategy. The current government indicated that the strategy will be published in 2013 and will include an emphasis on prevention, earlier diagnosis and access to memory clinics, as well as improved care across the disease course. The strategy will be able to draw on international examples of best practice and benefit from the experiences of other countries that have more advanced service provision. Meanwhile, the progress on the Irish strategy achieved thus far, demonstrates how philanthropic organisations can play a major influential and strategic role beyond merely the provision of financial support.

\section{(2) Strengthening Voluntary Organisations}

Building capacity has been critical in the voluntary sector, and Atlantic's early grantmaking to age-related voluntary organisations (2004-2008) attempted to address the relative under-developed and fragmented state of the sector by helping them to develop their operational structures, and strategic planning. Subsequent grant-making has continued this process and enabled the various organisations to develop a range of innovative initiatives. These include a peer-to-peer listening service for older people (Senior Helpline) and a re-granting programme (Age and Opportunity) that supports smaller organisations in meeting locally defined needs, whilst enhancing the development of strategic alliances and partnerships. Additionally, grants to 
disease-specific organisations reflect the prevalence of chronic disease in the older population (e.g., arthritis, stroke, dementia), and have focussed on strengthening advocacy with the aim of improving service provision. In the absence of a strong single organisation for older people, such as AARP (formerly the American Association of Retired Persons), a key feature of the investment in the voluntary sector, was the creation of two complementary and unique umbrella organisations: Older and Bolder and the Ageing Well Network.

Older and Bolder was established in 2006 to develop and strengthen the advocacy and policy capacity of its members ${ }^{3}$ underpinned by an equality and rights-based perspective. For example, there have been successful campaigns to protect the level of the state pension provision, which had been under threat in a number of government budgets. Consolidating the alliance and recognising the unique contribution of each affiliated organisation has been critical to the work of the alliance and the evidence suggests that the capacity for collaborative working has been enhanced through the sharing of knowledge, experience and expertise. Importantly, the ability of the alliance to present agreed policy positions has reduced the risk of "many competing voices" presenting a disparate range of issues (Carney 2009, 13). Several members of the Older and Bolder Alliance are also members of the Equality Rights Alliance which functions to protect and strengthen statutory and human rights infrastructure. Interestingly, Duncan (2008) has cautioned against relying on equality constructs, as the focus on age-equivalence and labour market issues has tended to de-prioritise old-age prejudice. Thus, the challenge for the Older and Bolder Alliance is to avoid limiting activism to "defending pension and welfare arrangements designed for a previous era", and to develop advocacy strategies that promote organisational, financial and social autonomy in older age (Duncan 2008, 1154).

The Ageing Well Network (AWN) was created by Atlantic in 2007, and is a leadership group that brings together the leaders and key decision makers from 75 organisations including representatives from the corporate sector, state agencies, academia and the voluntary sector. AWN differs from Older and Bolder in that it does not have a campaigning role; rather, it operates as an independent 'think-tank' and facilitates high-level strategic discussions between public, private and voluntary organisations. The inclusion of government representatives and civil servants at these meetings offers a unique opportunity for the network members to influence policy development and long-term planning. This is exemplified by AWN taking the lead in the roll-out of the Age Friendly Counties programme (see next section), the success of which is contingent on the support of decision makers in local government.

In addition to their work on the Age Friendly Counties, AWN have started to develop other projects including an integrated approach to supporting older people with multiple needs to remain in their own home; this builds on their expertise in bringing together decision makers and service providers. A separate initiative emphasises the more positive aspects of ageing, in terms of highlighting the considerable spending power of some older adults by encouraging businesses to respond to the needs of older consumers. This type of project may help to counteract the more pessimistic demographic 'time bomb' discourse that has tended to focus on dependency and the costs of care rather than on the positive socio-economic contributions made by older adults (Herring 2009, 13).

\footnotetext{
3 Current members are: Active Retirement Ireland, Age and Opportunity, Alzheimer Society of Ireland, Carers Association, Irish Hospice Foundation, Irish Senior Citizens Parliament, Older Women's Network and Senior Helpline
} 


\section{(3) Supporting the Implementation of Large-Scale Initiatives}

Older and Bolder and AWN have played a pivotal role in two critical initiatives: a National Positive Ageing Strategy and Age Friendly Counties (AFC) programme.

\section{(a) The National Positive Ageing Strategy}

Ireland has lagged behind other countries in developing and implementing strategies to inform ageing-related policies (e.g. New Zealand 2001; Northern Ireland 2005; Canada 2006; Wales 2008). As with the Dementia Strategy, Atlantic has played a pivotal role in ensuring a crossparty agreement to the development of a National Positive Ageing Strategy (NPAS) prior to the 2007 election. AWN has helped to set the policy agenda by bringing together a wide range of stakeholders and by formulating a position paper to inform the strategy (2012). The policy work of AWN has included the hosting of a national conference in 2012 designed to directly influence the content of the NPAS. AWN and the campaigning work by other Atlantic-funded groups has maintained pressure on subsequent governments, and this has continued during and after the public consultation process. Nevertheless, the lack of progress in producing even a draft of the strategy appears due, at least in part, to events largely outside of their control (i.e., change of government and public debt). It is likely that these events reduced the government's capacity for action needed for policy development (Nutbeam 2004, 138). Similar to other European countries, Ireland has had a Junior government minister with responsibility for older people (and the NPAS), but without real power (e.g., at cabinet level), these ministerial positions can become largely symbolic (Marier 2009,8). This lack of a 'champion' at the highest level of government may explain, at least in part, the protracted delays in developing ageing strategies and policies.

\section{(b) The Age Friendly Counties Programme (AFC)}

Until such time as the NPAS is published and implemented, one notable 'landmark' Atlanticfunded programme can do much, in the interim, to promote environments that are conducive to positive ageing. The development and implementation of the AFC initiative builds on the WHO's Global Age Friendly Cities initiative (WHO 2007) which provided a blueprint for the creation of inclusive, age-friendly cities and communities. The WHO guidelines ensure that there is a shared global understanding of what is meant by "age friendly"; this is particularly important because terms such as 'positive ageing', 'healthy ageing', 'active ageing' and 'successful ageing' are frequently used synonymously, yet have different connotations that are not always clearly articulated (Depp and Jeste 2006, 7 ).

The creation of age-friendly communities relies on a considerable degree of collaboration across public, private and voluntary organisations as well as representatives of older people themselves, service providers and business. The involvement of AWN in taking the lead in the roll-out of AFC has been an important element of the progress thus far. The ability to form working relationships and to influence senior members of county and local authorities, requires the kinds of skills, authority, and legitimacy of an organisation such as AWN, supported, in turn, by Atlantic.

The first county to receive an age-friendly designation was Louth; this is the smallest county in Ireland situated in the northeast corner, with a population of only $122,897^{4}$. The county town, Dundalk, was one of the original cities that participated in the Global Age Friendly Cities research project sponsored by WHO in 2006-2007. The knowledge gained during this process, together with a committed County Manager and the involvement of the local Institute of

\footnotetext{
${ }^{4}$ http://www.cso.ie/en/media/csoie/census/documents/census2011pdr/Tables\%20and\%20Appendices.pdf
} 
Technology, has meant that considerable progress, in consultation with older people, has been made across several relevant domains. These include an innovative 'smart-home' housing project in Dundalk, improved physical infrastructures in the outdoor environment that promote activity and participation (improved footpaths, lighting, seating etc.), and enhanced information provision via websites and drop-in centres. Such features form an integral part of creating an agefriendly community and, ideally, will promote improved social connectivity between the older person and their environment (Menec et al. 2011, 484). Furthermore, the establishment of forums of older people in each county/community should ensure that the views of older people are able to drive and influence local priorities. The type of information required to effectively plan for an ageing population has been difficult to source in Ireland (O'Shea and Conboy 2005, 4). Therefore, the knowledge base that will be developed during AFC implementation in an Irish context will, undoubtedly, be a rich and valuable resource. A key challenge, though, is the ability to use these findings in such a way as to make a real difference to everyday lives, not only for older people, but for the entire community. Additionally, a strong evaluation programme is required to assess overall impact (at individual and broader policy and societal level) both across counties and internationally (Menec et al. 2011, 487).

The roll-out of the AFC programme is continuing across Ireland and currently includes 8 out of the 29 county councils. An interesting international collaboration - part of an Ireland-Wales programme 2007-2013 - has emerged between two counties in the east of Ireland and three counties in Wales, thereby providing a unique opportunity to collaborate and share learnings across borders. Funding for this has come from the respective councils and AWN. This may facilitate the growth of a community of practice; furthermore, much can be learnt from the experience of other countries that may be further advanced in developing Age Friendly Communities. Interestingly, the Canadian government appears to have taken a strong leading role in the development of the initiative across Canada (Butler-Jones 2010). In Ireland, the work of Atlantic-created non-governmental organisation has done much to foster the necessary political commitment at both local and national level.

\section{Discussion}

Ireland is well positioned to learn from other countries/jurisdictions that have already encountered issues and concerns related to an ageing population. International examples of best practice have, amongst other things, informed the design of the Irish longitudinal study, research priorities, and a review of the evidence for the dementia strategy. Additionally, Atlantic has actively encouraged an all-island learning approach to ageing through joint grant-making with Northern Ireland and the establishment of a cross-border centre for ageing research (CARDI). Whilst national ageing strategies need to take into account specific cultural and societal contexts (Walker 2002, 125), much can be learnt from the success or otherwise, of strategies developed by other countries. Wales, a close neighbour of Ireland, provides an excellent example of integrated, participative policy making and practice (Welsh Assembly Government 2008); a key feature of their success was the appointment of the first Older People's Commissioner, who acts as a champion for older people across Wales with, importantly, associated legal powers. A similar post has recently been created in Northern Ireland and, while there does not appear to be plans for a commissioner for Ireland, this type of position may do much do advance an age-friendly ethos at the highest levels of policy making and implementation.

An essential aspect of Atlantic's objectives between 2008-2011 has been to increase and strengthen the organisational and research infrastructure in all dimensions of the age sector. Indeed, this is imperative if age-friendly principles are to be translated into tangible outcomes (Futureage 2011). Leadership is clearly critical in this regard, and Atlantic funding has facilitated the recruitment and retention of a number of highly respected researchers and clinicians. Importantly, the development, in parallel, of centres of expertise has also enabled the training and 
support of the next generation of researchers, geriatricians and policy professionals. However, there is still a need to establish a clear career structure, particularly at post-doctoral level, to encourage talented scholars to remain in the field. The voluntary sector too, has benefitted from the high level of energy and expertise of a core group of leaders, who have focussed not only on developing their organisational structures, but also on campaigning, advocacy, policy development and service delivery. Encouragingly, there is also evidence of less fragmentation and increased collaboration between voluntary groups. Collectively, these changes reflect a more mature and effective ageing sector, as does the increasing international recognition of Ireland as a centre for ageing research.

A significant proportion of Atlantic's funding has been directed towards health-related research and medical gerontology, but there has also been important support for other disciplines, as recommended in Futureage (2011), including social policy, housing and technology that supports independent living. As well as promoting research across disciplines, the funding of collaborative cross-institutional programmes, such as the longitudinal study on ageing, is helping to improve infrastructure and expertise beyond the core of Atlantic's grantees. This is an important factor because, whilst Atlantic has tended to maintain a small cohort of grantees, the beneficial effects of its influence in the ageing sector ought to be more widespread to ensure that its full potential in Ireland is achieved. The progress made in developing capacity has been transformative; nevertheless, there are still some notable gaps in research. For example, there is a need for a more direct focus on prevention and health promotion to help to reduce the burden of chronic disease and, whilst the longitudinal study will generate important data during its lifetime, more could and should be done, in the interim, to address unequal ageing and age-related inequalities.

Additionally, it could be argued that research centres could do more to involve older people in, amongst other things, decision making about research priorities and the conduct of research. Older people's understanding of ageing and service needs can be far removed from that of researchers and scientists, making their involvement essential across all stages of the research process (Walker 2007, 482). The voluntary sector could take the lead in this regard as they are likely to have a more direct relationship with older people who comprise a large proportion of their membership, volunteer cohort and/or are recipients of their services. Indeed, some voluntary groups are already working with the university sector to develop their own research and evaluation skills. Encouragingly, as part of the AFC roll-out, older people have been recruited as co-researchers and have been actively involved in designing data collection instruments. The voluntary sector, therefore, has a critical role to play in strengthening the voice and social action of older people as articulated in the second of Atlantic's 2008-20011 objectives. To this end, Atlantic has supported a series of initiatives that promote and mobilise older adults as active members of organisations, volunteers and advocates. Nevertheless, more needs to be done and many of the issues related to hearing, recognising, and responding to, the voice of older people, lie in the deceptively difficult task of encouraging older people to contribute more actively in terms of co-creating their own solutions and being co-opted into campaigning for change; that is, becoming part of the 'change process'. There has been a move, particularly in the United States, towards viewing civic engagement among older adults as an important social movement, which has been variously described as political participation and active involvement in the life of one's community, or more frequently as volunteering in the public or private sector (Minkler and Holstein 2008, 201). Strengthening 'civic engagement' as a way of opening up opportunities for older people is admirable, as long as it does not inadvertently become an 'expectation' that deepens the divide between the fit and productive versus those who are no longer able (or willing) to make recognisable contributions (Minkler and Holstein 2008, 197).

Clearly, it is not possible for Atlantic to address all of the pressing health and economic issues in Ireland and, therefore, they have focused instead on a number of specific areas. For example, the success in protecting the state pension has been a major achievement that will have 
made a real difference for older adults at risk of poverty. Nevertheless, the maintenance of financial security is an ongoing concern that will continue to be a focus of advocacy initiatives. The health priorities of Atlantic have included addressing service improvements in dementia and stroke care. However, it will take some time to determine the impact of the proposed dementia strategy. Work on stroke care is more advanced and the collaboration between voluntary groups and clinical experts seems to have been a critical component in producing successful targeted advocacy programmes to ensure government action and progression of policy initiatives. The NPAS, once developed ${ }^{5}$ and implemented, coupled with the successful roll-out of the AFC programme, offer considerable potential to make a real difference to the well-being of older people by creating environments and opportunities that support healthy active ageing (Walker 2002). The specific impacts of these initiatives are only likely to become evident in the mid- to longer-term because the process of becoming age-friendly is more than the immediate cosmetic additions to the environment. The required societal change may take some time to materialise and become truly transformative; nonetheless, significant progress has been made, to date, as celebrated most recently, in the hosting by Ireland of the first International Conference on AgeFriendly Cities in 2011.

It must be acknowledged that significant problems remain in the, albeit more vibrant and rapidly changing, ageing sector in Ireland. In particular, the provision of co-ordinated, timely, effective and responsive health and social care continues to be a major challenge, particularly in view of potential cuts as the government continues to implement austerity measures. In response, Atlantic have planned a more directed approach to meeting specific challenges as they move to the end of their grant-making in 2016. These focus firstly, on improving dementia care and services based in the home and community, and secondly to levering the implementation of the NPAS. Together, these appear to represent a logical and meaningful progression of the work conducted, to date, and build on the relationships already forged between the key players. However, as with the NPAS and AFC, the extent to which these objectives are achievable will necessitate the 'buy-in' of those at the frontline of policy making and service delivery. This underlines the continuing importance of Atlantic's role in developing research capacity, and the provision of high quality evidence to support change, as well as their ability to foster collaboration between key stakeholders.

As already mentioned, the full impact of Atlantic's investment will only be realised in the longer term, and there is still work to be done, particularly in relation to the full implementation of strategies to support positive healthy ageing and reduce inequalities. Nevertheless, the significant progress that has already been achieved has the potential to make a real difference to the lives of Irish people as they age, and Atlantic's legacy could be a more civic, responsive and age friendly society that will more than match international exemplars.

\section{Acknowledgements}

The evaluation team would like to extend their warmest thanks to all of the participants who contributed information and took part in interviews and related activities and to the Atlantic Philanthropies (Ireland) for their continuing help and support.

\footnotetext{
${ }^{5}$ The National Positive Ageing Strategy was officially launched in April 2013
} 


\section{REFERENCES}

Ageing Well Network. 2012. The New Agenda on Ageing: to Make Ireland the Best Country to Grow Old In. Dublin: Ageing Well Network.

Barrett Alan, George Savva, Virpi Timonen and Rose-Anne Kenny. eds. 2011. Fifty Plus in Ireland 2011. First Results from the Irish Longitudinal Study on Ageing (TILDA) http://www.tcd.ie/tilda/assets/pdf/glossy/Tilda_Master_First_Findings_Report.pdf.

Breeze, Beth, Barbara M. Gouwenberg, Theo, N.M. Schuyt, and Ian Wilkinson. 2011. "What Role for Public Policy in Promoting Philanthropy? The Case of EU Universities”. Public Management Review 13(8): 1179-1195.

Butler-Jones, David. 2010. The Chief Public Health Officer's Report on the State of Public Health in Canada, 2010: Growing Older - Adding Life to Years. Ottawa, Canada: Public Health Agency of Canada.

CARDI (Centre for Ageing Research and Development in Ireland).2009. Mapping Research in Ireland Against the UN Agenda on Ageing for the $21^{\text {st }}$ Century. Dublin: CARDI.

CARDI (Centre for Ageing Research and Development in Ireland). 2010. A Picture of Ageing Research: Ageing Research in Ireland, North and South. Dublin: CARDI.

Carney, Gemma, M. 2009. “Citizenship and Structured Dependency: The Implications of Policy Design for Senior Political Power”. Ageing and Society doi:10.1017/So144686X09990110

Central Statistics Office (CSO). 2007. Ageing in Ireland 2007. Dublin: Stationary Office.

Central Statistics Office (CSO). 2012. Profile 2 Older and Younger. Dublin: Stationary Office.

Department of Health. 1988. The Years Ahead: A Policy for the Elderly. Dublin: Stationary Office.

Depp, Colin A. and Dilip, V. Jeste. 2006. "Definitions and Predictors of Successful Aging: a Comprehensive Review of Larger Quantitative Studies”. American Journal of Geriatric Psychiatry 14 (1): 6-20.

Duncan, Colin. 2008. "The Dangers and Limitations of Equality Agendas as Means for Tackling Old-Age Prejudice”. Ageing and Society 28 (8): 1133-58.

Futurage. 2011. A Road Map for European Ageing Research. http://futurage.group.shef.ac.uk/ road-map.html

Hagan Hennessy, Catherine and Alan Walker. 2011. "Promoting Multi-disciplinary and Interdisciplinary Ageing Research in the United Kingdom”. Ageing and Society 31 (01): 5269.

HEA(Higher Education Authority). 2007. Research Infrastructure in Ireland: Building for Tomorrow. Report of the International Steering Committee. Dublin: HEA and Forfas.

Herring, Jonathan. 2009. Older People in Law and Society. Oxford: Oxford University Press.

Marier, Patrik. 2009. Aging Strategies in the United States. http://www.cccg.umontreal.ca/rc19/ PDF/Marier-P_Rc192009.pdf.

Menec, Verena H., Robin Means, Nora Keating, Graham Parkhurst, and Jacquie Eales. 2011. “Conceptualising Age-friendly Communities”. Canadian Journal on Aging 30 (3): 479493.

Minkler, Meredith, and Martha, B. Holstein. 2008. "From Civil Rights to Civic Engagement? Concerns of Two Older Critical Gerontologists About a 'New Social Movement' and What it Portends”. Journal of Aging Studies 22: 196-204.

NESF (National Economic and Social Forum). 2005. Care for Older People, Report No. 32. Dublin: NESF.

New Zealand Ministry of Social Development. 2008. Positive Ageing Goals and Objectives. New Zealand: New Zealand Ministry of Social Development.

Nutbeam, Don. 2004. "Getting Evidence into Policy and Practice to Address Health Inequalities”. Health Promotion International 19 (2): 134-140. 
O'Neill Des and Shaun O'Keefe. 2003. "Health Care for Older People in Ireland”. Journal of the American Geriatric Society 51 (9): 1280-1286.

O’Neill, Des, Cillian Twomey, and Eamon O’Shea. 2009. “Ireland”. In The International Handbook on Aging edited by Erdman Palmore, Suzanne Kunkel, and Frank Whittington, 283-296 Santa Barbara : Praeger Pubs.

O’Shea Eamon and Siobhán O’Reilly. 1999. An Action Plan on Dementia. Dublin: NCAOP.

O’Shea Eamon and Patricia Conboy. 2005. Planning for an Ageing Population: Strategic Considerations. Dublin: National Council on Ageing and Older People.

OFMDFM (Office of the First Minister and Deputy First Minister). 2005. Ageing in an Inclusive Society. Northern Ireland: OFMDFM.

Olshansky, S. Jay, Simon Biggs, W. Andrew Achenbaum, Linda Fried, Gloria Gutman, Alexandre Kalache, Kay-Tee Khaw, Alvaro Fernandez, Suresh, I.S. Rattan, Renato Maia Guimarães, Colin Milner, and Robert N. Butler. 2011. "The Global Agenda Council on the Ageing Society: Policy Principles”. Global Policy 2 (1). Doi: 10.1111/j.1758-5899.2010.00053.x

PHAC (Public Health Agency of Canada). 2006. Healthy Aging in Canada: A New Vision, A Vital Investment. Ottawa: PHAC, Division of Ageing and Seniors.

Pierce, Maria, Siobhán, H. Fitzgerald, and Virpi Timonen. 2010. Summary and Comparison of Key Social Provisions for Older People in the Republic of Ireland and Northern Ireland. Dublin: Social Policy and Ageing Research Centre, Trinity College Dublin.

Walker, Alan. 2002. “A Strategy for Active Ageing”. International Social Security Review 55 (1): 121-140.

Walker, Alan. 2007. "Why Involve Older People in Research”. Age and Ageing 36: 481-483.

Warnes, Tony and Judith Phillips. 2007. "Progress in gerontology: where are we going now?" In Critical perspectives on ageing societies, edited by Miriam Bernard and Tom Scharf, 139-155. Bristol The Policy Press.

Welsh Assembly Government. 2008. The Strategies for Older People in Wales 2008-2013: Living Longer, Living Better. Cardiff: Welsh Assembly Government.

World Health Organisation. 2001. Active Ageing: From Evidence to Action. Geneva: WHO.

World Health Organisation. 2007. Global Age-friendly Cities: A guide. France: WHO.

\section{ABOUT THE AUTHORS}

Dr. Andy Cochrane: Dr. Cochrane is a research psychologist and has been involved in agerelated research for the past five years. She is currently conducting a Cochrane systematic review assessing the effectiveness of 're-ablement-based' services for older people.

Dr. Sinéad McGilloway: Dr. McGilloway is a senior academic and community/public health psychologist. She has many years of experience in undertaking applied policy-relevant health and social care research and has been involved in a wide range of research programs and studies based on mixed methodologies.

Mairéad Furlong: Furlong is a psychologist with extensive research experience, focusing on evaluating the effectiveness of community-based projects designed to improve the lives of children and their families.

Dr. Michael Donnelly: Dr. Donnelly is a social and behavioural scientist, with an extensive record in applied health and social care research. He has considerable experience in the assessment and evaluation of service quality and the operation and management of public services. 

The International Journal of Aging and Society provides an international forum for the discussion of a rapidly growing segment of the population, in developed countries as well as in developing countries. Contributions range from broad theoretical and global policy explorations, to detailed studies of the specific human physiological, health, economic and social dynamics of aging in today's global society. The journal is a focal point for interdisciplinary research involving psychology, neuroscience, economics, sociology, anthropology, demography, nursing, biology, medicine, public health, epidemiology, gerontology, pharmacology, dentistry, health behavior and health education, "third age" education, management, marketing and communications. Articles cover a range from big picture questions of public policy to the fine detail of research and practice-based discussion.

The International Journal of Aging and Society is a peer-reviewed scholarly journal.

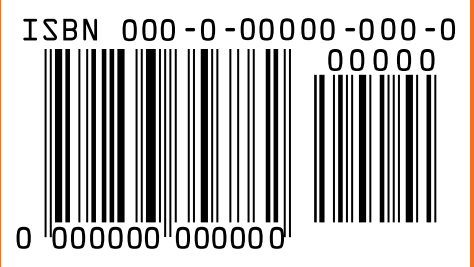

